\title{
DANTE ALIGHIERI \\ UMA EVOCAÇÃO SETECENTENÁRIA
}

\author{
Luígi Castagnola \\ (Untversidade Federal do Paraná)
}

Dos três grandes literatos italianos do século XIV Dante, Petrarca, Boccáccio - o primeiro em ordem de tempo e de importância é, sem dúvida, Dante Alighieri. Foi êle um espírito latino e universal, tendo direito à admiração dos homens. Que a Itália e Florença celebrem com ufania o sétimo centenário do nascimento de seu maior poeta, é compreensível: para os Italianos é um dever de gratidão, para os Florentinos é outrossim mais uma ocasião de fazer justiça a seu maior cidadão, que ódios políticos baniram desumanamente da pátria. Que nações e povos neolatinos prestem sua homenagem a um dos maiores literatos da neolatinidade é ato de fraternidade cultural e gentileza neolatina. Mas é surpreendente e significativo que a Rússia também queira comemorar com festejos oficiais o nascimento do autor da Divina Commédia. Isto significa que Dante interessa tôda a humanidade, ainda hoje, sete séculos após seu aparecimento sôbre a terra.

Nasceu o atribulado poeta florentino nos últimos dias de maio ou no comêço de junho de 1265. Embora nascido de família nobre, conquanto modesta, numa cidade já então famosa e pujante, não se conhece o dia de seu nascimento (1). Personagem amplamente estudada pelos doutos e tornada popular através dos séculos, sua vida foi pesquisada por historia-

1) No Paradiso (XXII, 112-117), Dante diz claramente que nasceu entre a segunda metade de malo e a primeira metade de Junho. C1. La Divina Commedia, Paradiso, comentada por Dłno Provenzal, Mondadort, Miláo, 1945, p. 826. O poeta fol batizado no "bel San Glovanni", em Florença, onde a certmônla do batımo era reallzada sòmente uma vez por ano, no sábado santo. Fram tåo numerosas as crianças a serem batizadas, que "i battezzatorl, escreve Plero Bargellinl, non avevano neppure il tempo di registrare 1 noml del battezzatl, e si limitavano a gettare in un rassio d'argento una fava nera per 1 maschi, bianca per le femmine". Cl. Plero Bargellinl, Vita di Dante, Vallecclil, Firenze, 1964, pp. 27-28. 
dores e literatos, mas sem grandes resultados, e não poucas lendas foram tecidas sôbre o fantástico visitador dos três reinos do Além-túmulo.

As incertezas envolvem o próprio nome, que os antigos documentos nos legaram de formas diferentes: Alagheri, Alleghieri, Aldighieri, e outras ainda. A forma mais legítima parece a de Alaghieri, embora prevalecesse a de Alighieri, graças à autoridade de Boccáccio.

Dante ufana-se de ser descendente dos romanos que fundaram Florença; seja como fôr, é històricamente certo que foi seu trisavô o cavaleiro Cacciaguida, o qual tombou pela libertação da Terra Santa, combatendo sob as ordens do imperador Conrado III. Cacciaguida havia casado com uma mulher do vale do rio Pó, a qual deu ao filho o nome de Alaghiero (2); dai a família dos Alaghieri. Do casamento de Alaghiero com uma florentina nasceu Bellincione, cujo filho, Alaghiero II, foi o pai de Dante Alighieri. Pouco se sabe a respeito do pai, que casou de nôvo, depois da morte da primeira mulher, Bella, mãe do poeta.

Conforme o costume da época, quando o poeta não tinha ainda doze anos, seu pai fêz lavrar ato civil de futuro casamento de Dante com Gemma Donati, mais jovem ainda. Desconhecido é o ano em que se realizou o matrimônio, mas, em 1302, Dante já tinha três filhos: Pietro, Iácopo e Antônia.

Da infância e da mocidade de Dante, bem como de seus estudos, ficaram escassas notícias. Na Vita Nuova (3), Dante afirma que aprendeu a poetar por si mesmo; aos dezoito anos trocou tenções poéticas com outros rimadores de amor; foi amigo de Giotto, pintor, de Oderísi de Gúbio, miniaturista, de Casella, músico e cantor, de Belacqua, fabricante de instrumentos musicais, de Brunetto Latini, político e homem de letras, de Guido Cavalcanti, poeta e cavaleiro, expoente do "dolce stil nuovo". Dedicou-se ao estudo não só da poesia em língua vulgar, provençal e italiana, mas também da latina, tendo predileção especial por Virgílio, o maior vate da latinidade, que, na Divina Commédia, Dante saúda com um tercêto famoso:

2) Com tôda probabilidade, trata-se do sobrenome do pai da espôsa de Cacclagutáa.

3) Vita Nuova, III. 
"Tu sei il mio maestro e il mio autore;

tu sei solo colui da cui io tolsi

lo bello stile che m'ha fatto onore" (4).

La Vita Nuova deixa ver que o jovem Dante não desdenhava a companhia alegre dos coetâneos, moços e donzelas, tomando parte ativa na vida galante florentina. Desabrochou assim seu amor por Beatriz; fato que, juntamente com o exílio, haveria de ter uma imporância extraordinária na vida e na arte do poeta. Em 1289, Dante já tomava parte na vida pública. Com efeito, na qualidade de soldado da cavalaria, tomou parte na batalha de Campaldino (1289), em que Florença e os guelfos derrotaram o exército aretino e os gibelinos de Toscana. Foi um acontecimento importante, porque fêz desaparecer, em Florença, o partido dos gibelinos; além disso, em Campaldino combateram juntos, contra os aretinos, Vieri de' Cerchi e Corso Donati, que se tornariam, pouco tempo depois, os chefes de duas facções guelfas em luta pelo govêrno de Florença: a dos Bianchi e a dos Neri.

Em 1290, faleceu Beatriz, filha de Folco Portinari; fôra espôsa de Simone dei Bardi, que pertencia a uma família de banqueiros poderosos na Itália e na Europa de então. Após a morte de Beatriz, o espírito de Dante sofreu uma perturbaçāo profunda e foi abalado por uma crise religiosa que o levou a procurar consôlo no estudo da filosofia e da teologia. Os Dominicanos explicavam, naqueles anos, as obras de Santo Tomás de Aquino e de Santo Alberto Magno na igreja de Santa Maria Novella, e os Franciscanos as obras dos místicos medievais e de São Boaventura na igreja de Santa Croce; Dante, como escreve no Convivio (5), freqüentou "le scuole de li religiosi" e "le disputazioni de li filosofanti".

"Come per me fu perduto lo primo diletto de la mia anima, io rimasi di tanta tristizia punto, che conforto non mi valeva alcuno" (6). "Tuttavia, dopo alquanto tempo. . . misimi a leggere... Boezio... e Tullio".

Leu, assim, o De consolatione philosophiae, de Boécio, e o De amicitia, de Cicero. A leitura dêsses livros - que Dante

4) Inferno, I, 85-87.

5) Convivio, II, 12.

6) Convivio, II, 12. 
achava difícil, por causa de seu pouco preparo filosófico e de seu escasso conhecimento do latim -, e as aulas dos religiosos, além de proporcionar confôrto espiritual ao poeta, descobriram-lhe o vasto mundo da filosofia e da teologia.

"E sì come essere suole che l'uomo va cercando argento e fuori de la intenzione truova oro,... . io, che cercava di consolarme, trovai non solamente a le mie lagrime rimedio, ma covabuli d'autori e di scienze e di libri: li quali considerando, giudicava bene che la filosofia, che era donna di questi autori, di queste scienze e di questi libri, fosse somma cosa. E immaginava lei fatta come una donna gentile" (7).

Dedicou-se com tamanha paixão à "bellissima e nobilissima' filosofia que, não sòmente se esqueceu momentâneamente de Beatriz, mas até adoeceu; sua vista se ofuscou e teve que ficar longo tempo na escuridão. Declara no Convivio que foram seus mestres Aristóteles e Santo Tomás de Aquino; mas estudou certamente também os outros autores e enfrentou com a fôrça de seu gênio os mais árduos e perigosos problemas metafísicos e religiosos; seu intelecto foi por algum tempo atormentado pela dúvida, chegando ao limiar da descrença. Viu-se então perdido numa selva tenebrosa, atirado ao mar tempestuoso como um frágil navio sem leme; viu-se a caminho do nada, e correu o perigo de afastar-se da ortodoxia religiosa. Referem-se a esta trágica luta espiritual os tercetos que iniciam, tão dramàticamente, a Divina Commédia:

"Nel mezzo del cammim di nostra vita mi ritrovai per una selva oscura che la diritta via era smarrita.

Ah quanto a dir qual era è cosa dura esta selva selvaggia e aspra e forte che nel pensier rinnova la paura!

Tant'è amara che poco è più morte" (8).

Como muitos outros grandes intelectos, Dante saiu vitorioso desta crise metafísico-religiosa, graças à sua honestidade intelectual e à fôrça de seu gênio. A alegria desta vitória es-

7) Convivio, II, 12.

8) Inferno, I, 1-7. 
piritual é jubilosamente expressa no último verso do Purgatório, em que o poeta se declara completamente renovado como uma nova fronde,

"puro e disposto a salire a le stelle" (9).

Quando adolescente, Dante viu em Beatriz uma "criatura celestial" (10), destruidora de todos os vícios e rainha de tôdas as virtudes (11), tão cheia de perfeição que o Paraíso sem ela é imperfeito (12); afinal, Beatriz é uma coisa nova, diferente dos outros mortais, afugenta os maus e torna virtuosos e gentis todos os que olham para ela (13),

"e par che sia una cosa venuta

dal cielo in terra a miràcol mostrare" (14).

Agora Dante, apaixonado pela formosíssima filosofia, isto é, pela sabedoria das coisas humanas e divinas, conforme a linguagem medieval, tem por ela palavras e elogios não muito diferentes dos que expendeu por Beatriz.

"Dico e affermo che la donna di cui io innamorai appresso lo primo amore fu la bellissima e onestissima figlia de lo imperadore de lo universo, a la quale Pittagora pose nome Filosofia". "Questa donna gentilissima Filosofia... è piena di dolcezza, ornata d'onestade, mirabile di savere, gloriosa di libertade". "Chi veder vuol la salute, Faccia che li occhi d'esta donna miri". "Veramente in voi (filosofia) è la salute, per la quale si fa beato chi vi guarda, e salvo da la morte de la ignoranza e da li vizii" (15).

Então Dante, que nunca se esqueceu para sempre de Beatriz, idealiza-a, transformando-a em símbolo da sabedoria das coisas humanas e divinas. De fato, o poeta, ao terminar a Vita Nuova, tomou a resolução de "non dire più di questa benedetta infino a tanto che io potesse più degnamente trattare di lei" (16), e manteve a promessa na Divina Commedia.

9) Purgatorio, XXXIII, 145.

10) Vita Nuova, II; XXI.

11) Vita Nuova, $\mathbf{x}$.

12) Vita Nuova, $\mathrm{XIX}$.

13) Vita Nuova, XXI.

14) Vita Nuova, XXVI.

15) Convivio, II, 15.

16) Vita Nuova, XLII. 
Rico dessas experiências, com a mente iluminada por novos e mais amplos horizontes culturais, robustecido seu espirito pela superada crise matafísico-religiosa, Dante faz seu ingresso no mundo da política.

Em 1295, toma parte no govêrno de Florença. Para tanto tivera que ingressar na corporação dos médicos e dos farmacêuticos (17), não permitindo a lei que os nobres entrassem na vida política sem pertencer a uma corporação. Fêz parte do Conselho Especial do Capitão do Povo (de novembro de 1295 até abril de 1296); do Conselho dos Sábios (dezembro de 1295); do Conselho dos Cem (de maio de 1295 até setembro de 1296). Além de outros encargos, que certamente exerceu, foi enviado, na qualidade de embaixador, a San Gemignano, em 1300; em 14 de junho do mesmo ano, foi eleito membro da Senhoria na qualidade de prior, o cargo político mais importante de Florença. Quando prior, Dante aprovou a condenação de três cidadãos florentinos que, em Roma, estavam trabalhando para entregar politicamente Florença ao Papa Bonifácio VIII. Irritado com isto, o famoso Papa enviava a Florença um legado, o cardeal Matteo d'Acquasparta, que, nada tendo conseguido do que queria, deixava a cidade após ter lançado sôbre ela o interdicto. Entrementes, Dante saíra do cargo (15 de agôsto), conforme a lei mandava. No mesmo ano foi a Roma para lucrar o jubileu, e grande foi sua emoção ao visitar a capital da cristandade e o solo onde antigamente viveram numerosos "cittadini divini" (18) do Império Romano. Ao escrever o Convivio, estava nêle ainda tão viva essa impressão, que podia afirmar:

"Certo di ferma sono oppinione che le pietre che ne le mura sue (de Roma) stanno siano degne di reverenzia, e lo suolo dov'ella siede sia degno oltre quello che per li uomini è predicato e approvato" (19).

Mas a política devia ser fatal ao poeta florentino. Na sua cidade as duas facções do partido guelfo, a dos Neri e a dos Bianchi, se acusavam e estraçalhavam mùtuamente. Para apaziguá-las, Bonifácio VIII solicitava a vinda à Itália de Car-

17) Dante entrou nesta corporaçáo, provàvelmente pela malor relaçı́o que havla então entre a mediclna e a fllosofia.

18) Convivio, IV, 5.

19) Convivio, IV, 5. 
los de Valois, irmão do rei da França; na realidade, o papa desejava auxiliar os Neri e levá-los ao govêrno de Florença. Quando Carlos já estava perto da cidade, a Senhoria, governada pelos Bianchi, resolveu enviar três embaixadores ao papa a fim de demovê-lo de seus planos. Dante era um dêles. Boccáccio relata que, ao ser escolhido para a difícil missão, o poeta haveria pronunciado estas palavras: "Se eu fôr, quem ficará? e se eu ficar, quem irá?" Bonifácio VIII exigia que os florentinos fizessem a vontade dêle e, segurando Dante, mandava de volta seus dois companheiros. Entrementes, em Florença as coisas chegavam a lim trágico desfecho: Carlos de Valois entrava na cidade, os Neri tomavam o govêrno e começavam as perseguições, os saques e as vinganças. Em janeiro de 1302, Dante é condenado ao degrêdo por dois anos e a pagar a multa de 5.000 florins sob a acusação de diversos crimes. A sentença não se escudava em provas concretas, mas ùnicamente na fama pública referente. Estando as paixões políticas desencadeadas, Dante compreendeu que era inútil apresentar-se para se defender, e, tendo abandonado Roma, não voltou a Florença. Em março do mesmo ano, foi declarado contumaz e condenado a ser queimado vivo, se fôsse prêso no território da Senhoria. Nunca mais Dante havia de ver sua cidade natal. Foi uma sentença injusta, como tantas outras na trágica história das reviravoltas políticas. Começou assim o triste exílio do poeta, o longo caminho semeado de amarguras, de sofrimentos e de espinhos dos quais haveria de desabrochar a flor da poesia, a Divina Commédia, a obra-prima da literatura italiana. $O$ amargor do injustiçado e degredado Dante expressou nos versos em que seu trisavô Cacciaguida, encontrado no céu de Marte, lhe profetiza o exílio:

"Tu lascerai ogni cosa diletta più caramente; e questo è quello strale che l'arco de lo esilio pria saetta.

Tu proverai sì come sa di sale lo pane altrui, e come è duro calle lo scendere e il salir per l'altrui scale.

$E$ quel che più ti graverà le spalle, sarà la compagnia malvagia e scempia con la qual tu cadrai in questa valle; 
che tutta ingrata, tutta matta ed empia

si farà contr' a te; ma, poco appresso

ella, non tu, n'avrà rossa la tempia.

Di sua bestialità il suo processo

farà la prova; sì che a te fia bello

averti fatta parte per te stesso" (20).

Essa companhia "malvagia e scempia" foram os companheiros políticos de Dante, os Bianchi banidos de Florença; no comêço do exílio, o poeta tentou voltar com êles à pátria, combatendo; mas logo os abandonou por serem homens medíocres, sedentos de vingança e sem nobres ideais. Tanto assim, que pensaram em matar Dante. Odiado pelos Neri e pelos Bianchi, o grande florentino foi peregrinando por tôda a Itália, levando no coração um imenso desejo de voltar à pátria, uma saudosa esperança que êle acalentaria por longos anos.

"Poi che fu piacere de li cittadini de la bellissima e famosissima figlia di Roma, Fiorenza, di gittarmi fuori del suo dolce seno - nel quale nato e nutrito fui in fino al colmo de la vita mia, e nel quale, con buona pace di quella, desidero con tutto lo cuore di riposare l'animo stancato e terminare lo tempo che m'è dato per le parti quasi tutte a le quali questa lingua si stende, peregrino, quasi mendicando, sono andato, mostrando contra mia voglia la piaga de la fortuna, che suole ingiustamente al piagato molte volte essere imputata. Veramente io sono stato legno sanza vela e sanza governo, portato a diversi porti e foci e liti dal vento secco che vapora la dolorosa povertade" (21).

Por estas palavras se pode avaliar a dor do poeta, que viu também envilecida entre os estrangeiros sua fama de literato, granjeada com as obras já escritas, e comprometida a glória que poderia alcançar com as obras futuras.

Não se conhecem tôdas as etapas da longa peregrinação de Dante Alighieri. No comêço foi hóspede de Bartolomeo della Scala, em Verona; depois estêve em Treviso, Pádua e Bolonha; em 1306, foi hóspede muito honrado na côrte dos marqueses

20) Paradiso, XVII, 53-69.

21) Convivio, $1,3$. 
Malaspina, na Ligúria oriental; a seguir passou algum tempo em Lucca, e Boccáccio afirma que, em 1310, foi a Paris. Naquele mesmo ano, o imperador Arrigo VII descia à Itália, e Dante saudou-o com palavras de admiraçāo e esperança, dirigindo uma carta aos príncipes da Itália a fim de que o recebessem como um enviado da Providência divina, e outra aos scelestissimis florentinis, ameaçando-lhes merecido castigo pela oposição que faziam ao imperador. Arrigo, porém, falecia em 1313, em Buonconvento; esvaeceu-se talvez então definitivamente a esperança do retôrno. Seja como fôr, Dante continuou com afinco a composição da Divina Commédia; ainda no canto 25 do Paradiso, parece acalentar a ilusão de que os cruéis florentinos, diante da fama grangeada pelo poema sacro e da saúde alquebrada do poeta, ficariam enternecidos e permitiriam sua volta à pátria.

"Se mai continga che il poema sacro, al quale ha posto mano e cielo e terra, sì che m'ha fatto per più anni macro,

vinca la crudeltà che fuor mi serra del bello ovile ov'io dormii agnello, nimico ai lupi che gli danno guerra;

con altra voce omai, con altro vello ritonerò poeta; ed in sul fonte del mio battesmo prenderò il cappello" (22).

Mas a esperança foi vã até o fim; em 1315, o govêrno florentino confirmava de nôvo a condenação de Dante à morte e, desta vez, juntamente com os filhos. O poeta estava então em Verona, na côrte de Cangrande dalla Scala. Entre 1317 e 1318, Guido Novello da Polenta, senhor de Ravena, convidava Dante à sua côrte, e o convite foi aceito. Chamou para junto de si os filhos e, provàvelmente, estava com êle também sua espôsa. Em Ravena passou os últimos quatro anos de sua existência, honrado e estimado, afastando-se sòmente para fazer algumas viagens às cidades vizinhas. Em Mântua, em fins de 1319, estêve presente a uma discussão, cujo tema era então muito debatido: se nalgum lugar da esfera terrestre a água estivesse mais alta do que a terra. Êle achava que não, e

22) Paradiso, XXV, 1-9. 
difendeu sua opinião em janeiro de 1320, na pequena igreja de Santa Helena, em Verona, diante do clero da cidade.

A vida do poeta estava perto de seu fim. O poema estava acabado; a fama de seu autor era grande, e sua missão neste mundo estava cumprida. No verão de 1321, foi a Veneza na qualidade de embaixador de Guido Novello da Polenta, e de volta a Ravena adoeceu gravemente, vindo a falecer na noite entre 13 e 14 de setembro de 1321. Seus despojos mortais fo. ram sepultados com grandes honras numa capela da igreja de São Francisco; mas devia passar ainda bastante tempo antes que pudessem descansar em paz. Em 1329, o cardeal Bertrando del Poggetto mandou queimar em praça pública o De Monarchia, e pretendia fazer o mesmo com os restos mortais do poeta, que foram salvos por pessoas amigas. Os Franciscanos cuidaram sempre carinhosamente do túmulo de Dante ,e diversas vêzes se opuseram aos Florentinos, que, após ter expulsado tão cruelmente da cidade o poeta quando estava vivo, para lá queriam transladá-lo depois de morto, tendo-se tornado famoso em todo o mundo. Na época do papa Leão X, florentino, os Franciscanos tiveram que ocultar o corpo de Dante para o subtrair à cobiça de Florença. Mais tarde, o cardeal Luigi Valenti Gonzaga mandou erguer um modesto mausoléu de mármore, que encerra até hoje o túmulo de Dante Alighieri.

"Grande foi seu gênio, escreve Rosário Tosto, profunda sua fé católica, fortíssimo seu caráter. Amou a poesia e o estudo, teve intuição pronta e feliz, pronfundo espírito de observação, fantasia rica, extraordinária capacidade de assimilação. Sua vida afetiva foi intensa, conheceu a audácia do pensamento que transpõe qualquer barreira e teve consciência de sua grandeza, aceitando entretanto o dogma e a tradição com humildade cristã. Acima de tudo foi homem de espírito harmônico e iluminado, italiano e universal. A sua vasta alma ofereceram matéria de reflexão e de experiência o estudo e o amor, a política e a ciência, a história e a filosofia, a natureza e suas vicissitudes pessoais; enfrentou os problemas que se lhe apresentaram com lúcido intelecto e ardor apaixonado. Personificou êle certamente a época da Idade Média, 
mas aos mesmo tempo transcendeu-a. Quis ser e foi, na verdade, um guia, um mestre de vida" (23).

Dante não foi um espírito introspectivo, como Petrarca. Seu intelecto voltou-se para os prementes e sempre atuais problemas da humanidade: o amor, a língua, a poesia, a ciência, a filosofia, a política, a religião. $\mathbf{E}$ por ter êle arrostado com a fôrça de seu gênio os problemas centrais da humanidade, impulsionado pelo desejo de solucioná-los com lealdade e honestidade intelectual é que a humanidade lhe devota imperecível gratidão e se interessa por êle e pela sua obra. Por isso, Dante é e será sempre "vivo" para a humanidade.

Viveu o grande florentino sòmente 56 anos; quase um decênio dedicou à vida pública, e 19 anos passou no atribulado e errante exílio. Apesar disso, sua obra foi monumental, sem par na literatura italiana. Se é verdade que Dante não estêve "sempre ocupado na leitura de pergaminhos, com o rosto franzido pelo esfôrço da meditação", nem passou "entre os homens, embuçado e carrancudo, sem lhes conceder um olhar, completamente absorto em pensamentos mais altos que as tôrres e as nuvens" (24), mas teve sua mocidade barulhenta e galante, é certo, porém, que não ficou prêso ao "pleiboísmo" de seu tempo.

"Andiam, ché la via lunga ne sospinge" (25), é um verso lapidar que impulsionou sempre Dante pelos caminhos do mundo, da ação e do pensamento, preocupado em nunca se deter em fatos, pessoas e questões de pouca monta ou fúteis.

Já com 28 anos de idade, escrevia em língua vulgar $L a$ Vita Nuova (26), coleção de rimas amorosas, ligadas e comentadas por prosas. E a história de seu amor simples e melancólico por Beatriz. Neste livrinho encontramos a primeira grande prosa de arte italiana e um documento fundamental do "estilnovismo", uma das poéticas mais originais da literatura

\footnotetext{
23) Rosárto TOSTO, História da Literatura Italiana, Editôra Vozes, Petrópolis, 1962, vol. I. pp. 68-69.

24) Glovannl PAPINI, Dante Vivo, Editöra Globo, Pórto Alegre, 1940, pp. 15-16. Tradução de Leonardo Mascello.

25) Inferno, IV, 22.

26) Esta obra fol composta entre 1292 e 1293.
} 
italiana. Mas o jovem homem de letras já alimenta sonhos e propósitos de grandeza. Nas palavras que encerram a Vita Nuova,

"se piacere sarà di colui a cui tutte le cose vivono, che la mia vita duri per alquanti anni, io spero di dicer di lei (Beatriz) quello che mai non fue detto d'alcuna" (27),

todos vislumbram a primeira idéia e a promessa da futura Divina Commédia.

A vida política de Dante teve um trágico desfecho: o destêrro, o confisco dos bens, a condenação à morte. Não esmorece em face de tudo isto o poeta. Volta às letras e quer demonstrar a todos, especialmente aos ingratos florentinos, seu saber. Escreverá, nos primeiros anos do exílio (28), o Convivio e o De Vulgari Eloquentia, duas obras ricas de erudição. Na primeira, em língua vulgar, pretende oferecer uma síntese do saber de então; na segunda, em latim, trata da origem da linguagem, em geral, e das línguas vulgares, em especial do italiano. Escolheu de propósito, parece, dois temas diferentes e duas línguas diversas para mostrar, ao mesmo tempo, sua cultura lingüística e científica. Acalentava a esperança de que os Florentinos se envergonhariam de ter banido da cidade um sábio e um poeta, e o convidaram a voltar.

O Convivio é um "banquete" cultural que Dante oferece aos que gostam de se instruir, mas não o podem fazer por lhes faltar o tempo ou desconhecerem a latim. A obra devia conter 14 canções (iguarias), cada uma acompanhada de seu comentário (pão); mas ficou interrompida no quarto tratado e sòmente três foram as canções comentadas. Encontramos nesta obra o apaixonado elogio que Dante faz da língua vulgar, uma luz nova que iluminará todo o povo, destinado a ficar nas trevas da ignorância por desconhecer o latim em que estão escritas as obras dos doutos.

"Questo (a lingua vulgar) sarà luce nuova, sole nuovo, lo quale surgerà là dove l'usato tramonterà, e darà

27) Vtta Nuova, XLII.

28) O Convivio fol escrito entre 1304 e 1307. O De Vulgari Eloquentia fol composto na mesma época do Convivio. 
lume a coloro che sono in tenebre e in oscuritade per lo usato sole (o latim) che a loro non luce" (29).

O De Vulgari Eloquentia, embora inacabado, tem especial importância lingüística, e contém os resultados das pesquisas de Dante relativas à origem da linguagem, à formação da língua vulgar italiana, e à arte literária. Para Dante, a língua literária da Itália "in qualibet rédolet civitate nec cubat in ulla" (30), isto é, ela exala seu perfume em todos os 14 principais dialetos falados pelos Italianos, mas não se encontra completamente em nenhum dêles, nem no "turpilóquio" dos Toscanos, embora êstes tolamente se gabem de a possuir êles sòmente. Portanto, segundo Dante, o italiano illustre, aulico, cardinale, curiale deverá ser formado tirando palavras de todos os dialetos.

Na Monarchia, escrita em latim (31), Dante Alighieri expōe algumas de suas idéias políticas. É a mais bem organizada de suas obras doutrinais, e abrange três livros: no primeiro é afirmada a necessidade da monarquia universal, mais idônea para garantir a paz e a felicidade dos homens; no segundo o autor sustenta que o império pertence de direito ao povo romano; no terceiro é defendida a doutrina política de que "a Autoridade do Império não depende de maneira nenhuma da Igreja" (32). No entanto, o famoso tratado termina com estas palavras:

"Esclarecida está a verdade da primeira questão, consistente em saber se para o bem do mundo era de mister o ofício do Monarca; e o da segunda, que consistia em estabelecer-se se o povo Romano se arrogava legìtimamente o Império; e também da terceira, que inquiria se a autoridade do Monarca dependia imediatamente de Deus ou de outra autoridade. Cumpre anotar que a verdade relativa a esta última questão não se pode admitir de tal forma estritamente que faça com

29) Convivio, I, 13.

30) De Vulgari Eloquentia, I, 16, 4. Devia conter 4 livros, mas Dante escreveu sòmente até o capitulo XIV do II livro.

31) O De Monarchia fol composto entre 1312-1313, conforme a oplniảo mals acelta.

32) De Monarchia, III, 15. Citamos a tradução felta por J. Penteado E. Stevenson, Ediçóes e Publicaçóes Brashl Editỏra, São Paulo, 1960, p. 235. Sóbre versóes braslleiras de Dante, cf. C. TAVARES BASTOS, Dante e Outros Poetas Italianos na Interpretação Brasileira, Gráflca Laemmert, 1953, Rio de Janeiro. 
que o Príncipe romano não se quede em nada submetido ao Romano Pontífice ;a felicidade mortal está de certa maneira condicionada à felicidade imortal. Cumpre a César empregar no que respeita a Pedro, a mesma reverência que o filho primogênito deve dispensar a seu pai, para que iluminado pela graça paternal, irradie com maior virtude sôbre o orbe terrestre, que lhe foi outorgado por Aquêle - o único governador de tôdas as coisas espirituais e temporais" (33).

São conhecidas as acirradas polêmicas antigas e modernas despertadas pelo De Monarchia, muitas delas devidas à falta de preparo cultural para a compreensão do conteúdo histórico e teorético do tão discutido tratado. Falou-se também do ideal político dantesco como de uma utopia política; mas o certo é que a experiência histórica acabou por mostrar que o ideal político de Dante Alighieri marcava - e marca ainda hoje mais do que nunca - o caminho da trágica história política da humanidade.

A glória poética de Dante pouco acrescentam as outras obras menores, tôdas elas escritas em latim: treze Epistolae (24), sendo ainda duvidosa a genuidade de algumas delas; duas Eglogae (35); a Quaestib de aqua et terra (36).

A obra-prima de Dante é a Divina Commedia; escrita em tercetos, em língua italiana, ainda hoje é o monumento poético mais importante e majestoso da literatura italiana.

O poeta começou a escrever o poema no exílio, entre 1306 e 1307; mas a idéia remonta certamente à época da Vita Nuova, quando Dante estava ainda em Florença. Trabalhou incansàvelmente até o fim da vida, em tôrno do "poema sacro", cujo titulo Dante escrevia com um só eme e pronunciava com o acento sôbre o i: Comedia. Foi Boccáccio que chamou "divina" esta obra; acréscimo feliz e unânimemente aceito pela tradição, que o respeitou até hoje. Donde o título atual: La Divina Commédia.

33) De Monarchía, ob. cit., p. 238.

34) Escritas entre 1304 e 1319.

35) Escritas, talvez, em 1319-1320. Foram dirigidas a Giovanni del Virgillo, gramático bolonhês e autor de poestas em latim.

36) L uma conferência lida em Verona, em 1320. 
Divide-se o poema em três cânticas: o Inferno, o Purgatório, o Paradiso. Cada uma dessas cânticas abrange trinta e três cantos; acrescentando-se o primeiro canto, que serve de introdução, o poema perfaz cem cantos.

La Divina Commédia (37) conta e canta a viagem de Dante aos três reinos do Além-túmulo para purificar-se a si mesmo e para purificar a humanidade. $O$ poeta, perdido numa selva trevosa, desesperançado de sua salvação, é socorrido por Virgílio, símbolo da razão humana, que o convida a fazer a viagem ultramundana. Guiado e auxiliado por Virgílio, Dante visita o Inferno, debaixo da terra. Chegado ao centro do globo, atravessa o esmisfério austral passando por uma perfuração natural e, ao voltar a ver as estrêlas, acha-se ao pé da montanha do Purgatório. Sempre guiado por Virgilio, sobe até o cume da montanha, onde está o antigo Paraíso Terrestre. Virgílio desaparece e se apresenta Beatriz, símbolo da revelação divina, que acompanhará Dante na visita ao Paraíso, formado por nove esferas concêntricas. No Empíreo, fora do tempo e do espaço, está Deus; lá termina a viagem e o poema de Dante, que, na última etapa de sua viagem, é acompanhado por São Bernardo, símbolo da vida contemplativa.

A fantástica e alegórica viagem realiza-se em 1300 , quando Bonifácio VIII havia promulgado o jubileu e o poeta contava com 35 anos de idade; tem início na noite da quintafeira santa (7 de abril) e termina na quinta-feira depois da Páscoa (14 de abril).

E claro que êste nosso mundo é projetado no mundo do além; Dante pode, assim, ver, falar, julgar, aprovar ou condenar homens e fatos do passado e do presente, e até permitirse, vez por outra, o luxo de ser profeta.

"A personagem mais viva da Commédia, escreve Rosário Tosto, é o próprio Dante, pecador e juiz, pronto à comoção e à ira, florentino e italiano, rico de impulsos ideais e de interêsses práticos, medieval e moderno, coerente e ilógico, igual e diverso. Por vêzes é de uma delicadeza quase feminina, por

37) Dante deu o título de Commedia so seu poema porque, como a comédia, tem um coméço triste e um finsıl sereno, e ainda porque o poeta usou o estilo médio (comico, conforme a terminologia dos estllos, exposta no De Vulgari Eloquentia), e nåo o estllo alto, isto é, trágico. 
vêzes de uma energia áspera e selvagem: condena Francisco e Ulisses e ao mesmo tempo admira-os; parece voltar os olhos ao céu e indaga, pelo contrário, o fundo da realidade humana e histórica; ora é simples e claro, ora sutil e hermético; ora crédulo e dogmático como um homem de seu tempo, ora audaz e inovador a ponto de roçar a heresia; por um lado louva - passado e celebra a antiga Florença de Cacciaguida, por outro olha para a frente e torna-se profeta do porvir. Mas duas qualidades todos lhe reconhecem concordemente: uma fantasia altíssima e uma grandíssima consciência moral... Foi êle um espírito latino e universal e tem direito à admiração imperecível dos homens" (38).

Escrevendo a Divina Commédia, Dante Alighieri deu à Itália a sua obra-prima poética e, por meio da língua, uniu moral e culturalmente os diferentes povos e os numerosos paises em que estava politicamente dividida então a península mediterrânea. Contribuiu, destarte, como ninguém para a futura unidade e independência política da Itália. Foi por isso que os Italianos, gratos ao maior poeta de sua terra e de sua estirpe, deram-lhe os dois gloriosos títulos de "Pai da língua italiana" e "Pai da Pátria".

38) Rosário TOSTO, Historia da Literatura Italiana, Editôra Vozes, Petrópolis, 1962, vol. I, p. 82. 